\title{
A CONVENÇÃO DE ISTAMBUL E O NOVO PARADIGMA DA VIO- LÊNCIA DE GÉNERO
}

\section{Resumo}

O novo paradigma da Convenção de Istambul, que concebe todas as formas de violência contra as mulheres como violência de género, criou a necessidade de alterações na ordem jurídica penal, entre as quais destacamos o alargamento do conceito legal de violação e de coação sexual a todos os atos sexuais não consentidos, a natureza pública do crime de violação e a aplicação de sanções legais, maxime criminais, ao assédio sexual.

Palavras-chave: violência de género; violação; coação sexual; assédio sexual.

\section{Abstract}

\section{Istanbul Convention and the new paradigm of gender violence}

The new paradigm of Istanbul Convention, that conceives all forms of violence against women as gender violence, created the need to reform the criminal law, for example, enlarging the legal concept of rape and sexual coercion to all non-consensual sexual acts; the public nature of rape; the punishment of sexual harassment with a legal sanction, maxime a criminal one.

Keywords: gender violence; rape; sexual coercion; sexual harassment.

\section{Resumé}

\section{La Convention d'Istambul et le nouveau paradigme de la violence de genre}

Le nouveau paradigme de la Convention d'Istanbul, qui conçoit toutes les formes de violence à $\mathrm{l}^{\prime}$ égard des femmes comme violence de genre, a créé la nécessité de reformer l'ordre juridique pénale pour introduire l'élargissement du concept de viol et de contrainte sexuelle à tous les actes sexuels non consensuels; la nature publique du crime de viol; la punition de l'harcèlement sexuel, maxime la criminalisation.

Mots-Clés: violence de genre; viol; contrainte sexuell; harcèlement sexuel.

\section{Introdução}

Este texto aborda os imperativos ético-jurídicos e constitucionais de criminalização na área da violência sexual, enquanto violência de género, referindo dois casos - a violação e o assédio sexual - em que a lei penal é insuficiente para proteger os direitos humanos das mulheres, nomeadamente a sua liberdade e autodeterminação sexual e integridade pessoal.

1 Centro de Estudos e Investigação em Direito da Universidade Católica Portuguesa. sottomayorclara@gmail.com 
A Convenção do Conselho da Europa para Prevenção e o Combate à Violência Contra as Mulheres e a Violência Doméstica, designada por Convenção de Istambul, foi ratificada por Portugal em 21 de janeiro de 2013 e entrou em vigor a 1 de Agosto de 2014.

Esta Convenção reflete um avanço ideológico e simbólico na teorização da violência contra as mulheres, ultrapassando-se a linguagem neutra em relação ao género, que tem sido adotada na legislação nacional (Lei n.o 112/2009, de 16 de Setembro), que não reconhece as mulheres como o principal grupo alvo de violência no seio da família. Pelo contrário, a Convenção, reconhecendo que existe violência contra homens, afirma que os vários tipos de violência nela descritos atingem de forma desproporcionada as mulheres e concebe a violência contra as mulheres como violência de género, de caráter estrutural e epidémico em todas as sociedades, e que tem sido legitimada como «natural» e «inevitável» pela cultura.

A Convenção reconhece a vida perigosa que as mulheres e as meninas têm de enfrentar no seu dia-a-dia - na família, na rua, na escola e no trabalho - bem como as práticas discriminatórias de que são alvo pelo único facto da pertença a um género, o feminino. É por isso, um documento virado para as mulheres e feito a pensar nelas, para garantir o seu direito a viver sem violência e sem medo.

\section{1. $O$ conceito de violência de género}

A Convenção de Istambul analisa a violência contra as mulheres numa perspetiva específica, que a distingue da violência dirigida contra os homens. Ela é composta por elementos históricos e culturais, que lhe conferem o significado político e ideológico de mecanismo social pelo qual as mulheres são forçadas a assumir uma posição de subordinação em relação aos homens. Para o efeito, a Convenção, para além dos conceitos de «violência contra as mulheres» e de «violência doméstica», usa o conceito de "género», termo através do qual designa os papéis, os comportamentos, as atividades e as atribuições socialmente construídos que uma sociedade considera apropriados para as mulheres e para os homens, e o conceito de "violência contra as mulheres baseada no género", que designa toda a violência dirigida contra uma mulher por ela ser mulher ou que afeta desproporcionalmente as mulheres.

Todas as formas de violência contra as mulheres, mesmo aquelas que têm sido trivializadas pela cultura, como o assédio sexual, são vistas como uma violação grave dos direitos humanos das mulheres e das meninas, e como um obstáculo à realização da igualdade entre as mulheres e os homens.

A Convenção considera que a realização de jure e de facto da igualdade entre mulheres e homens é um elemento chave na prevenção da violência contra as mulheres e que esta é uma manifestação das relações de poder historicamente desiguais entre mulheres e homens que conduziram à dominação das mulheres 
pelos homens, o que impediu aquelas de progredirem plenamente e de realizarem as suas potencialidades como pessoas.

A Convenção reconhece que também as meninas são vítimas de violência de género e que as crianças, de ambos os sexos, são vítimas indiretas de violência doméstica, pelo facto de assistirem às agressões praticadas por um dos pais contra o outro/a progenitor/a, a mãe, na maioria dos casos (RASI, 2013: 78 e 80).

Estas inovações conceituais e ideológicas têm por consequência a necessidade de proceder a alterações legislativas no direito português, em vários domínios, no direito da família e no direito penal, no processo civil e no processo penal.

A resistência oferecida à transposição da Convenção de Istambul para a ordem jurídica prende-se com uma desconfiança da sociedade e do poder político em relação à visão das mulheres como um grupo historicamente discriminado. $\mathrm{O}$ reconhecimento da natureza estrutural e histórica da discriminação das mulheres constitui um desafio ao sistema patriarcal, que concentrou o poder de decisão (político, económico e familiar) nas mãos dos homens. Por outro lado, confere às mulheres o estatuto de "credoras» do Estado e da sociedade, que ficam onerados com o dever de instituir medidas específicas para a construção da igualdade material ou de resultados, objetivos que exigem a adjudicação de recursos económicos que o Estado não quer despender. E não se pode esquecer que, beneficiando o Estado e a sociedade do trabalho gratuito (trabalho doméstico e cuidado de crianças, de pessoas idosas e portadoras de deficiência) ou menos remunerado das mulheres, o capitalismo, na vertente de neoliberalismo em que vivemos hoje, tem interesse em manter o sistema, não obstante a democratização do poder político e as suas leis formalmente igualitárias.

A crença na superioridade da cultura europeia, no que concerne ao respeito pelos direitos das mulheres, é posta em causa pela denúncia de discriminações e violências sofridas por estas, de forma sistemática, no seu quotidiano, como o assédio sexual nas ruas e no trabalho, a violência doméstica e a violação «não violenta».

Em conformidade com esta postura verificou-se uma maior facilidade, no Parlamento, em criminalizar comportamentos oriundos de culturas não europeias - mutilação genital feminina e casamento forçado - do que em criminalizar formas de violência sexual mais subtis contra as mulheres e cuja incriminação implicará restrições ao que tem sido considerado uma liberdade «natural» ou um privilégio dos homens. É o caso do alargamento do conceito de violação a atos sexuais de penetração não consentidos e praticados sem violência física ou ameaça grave e da coação sexual a todos os atos sexuais não consentidos (art. 36. ${ }^{\circ}$ ), bem como a punição (por via penal ou outra) do assédio sexual no trabalho e em lugares públicos (art. 40.).

Estas formas de violência permanecem silenciadas e banalizadas pela cultura, sem juízo de censura criminal, apesar da sua prática generalizada e dos efeitos traumáticos que geram nas mulheres, sobretudo durante a adolescência, a 
fase da vida em que são mais vulneráveis e em que mais precisam de segurança e de liberdade para desenvolverem, sem interferências, as suas potencialidades psíquicas, físicas e intelectuais.

\section{Violação e coação sexual}

2.1. O art. 36. $\stackrel{\circ}{\text {, n. }} \stackrel{1}{1}$ da Convencão estipula que os Estados deverão adotar as medidas legislativas ou outras que se revelem necessárias para assegurar a criminalização da conduta de quem intencionalmente a) Praticar a penetração vaginal, anal ou oral, de natureza sexual, de quaisquer partes do corpo ou objetos no corpo de outra pessoa, sem consentimento desta última; b) Praticar outros atos de natureza sexual não consentidos com uma pessoa; c) Levar outra pessoa a praticar atos de natureza sexual não consentidos com terceiro. O n. $\frac{\text { }}{2}$ da mesma disposição afirma que o consentimento tem de ser prestado voluntariamente, como manifestação da vontade livre da pessoa, avaliado no contexto das circunstâncias envolventes e o n. 3 afirma, de acordo com os inquéritos que demonstram que a maioria dos crimes sexuais ocorrem em contexto relacional, que a criminalização prevista no n. ${ }^{\circ} 1$ se aplica a atos praticados contra cônjuges ou companheiras/os ou contra ex-cônjuges ou ex-companheiras/os.

A Convenção de Istambul, exigindo a criminalização de qualquer ato sexual não consentido, impõe que nos crimes de violação e de coação sexual sejam abolidos os requisitos da violência e da ameaça grave, como elementos constitutivos dos tipos legais de crime previstos nos artigos $163 . \stackrel{\circ}{,}$ n..$^{\circ} 1$ e $164 .^{\circ}$, n. ${ }^{\circ} 1$ do CP. Impõe, também, no crime de coação sexual, o alargamento do âmbito da criminalização a todos os atos sexuais praticados sem consentimento de uma das partes, acabando com a distinção entre atos sexuais de relevo e atos sexuais sem relevo, distinção que foi responsável pela descriminalização, na prática judiciária, de muito atos ofensivos da liberdade sexual, antes da reforma de 2007, que passou a punir a importunação sexual (Sottomayor, 2007).

O crime de violação foi sempre concebido ao longo de todos os Códigos Penais que atravessaram a nossa história, como um crime de execução vinculada, isto é, que exige, para estar preenchido, meios típicos de constrangimento, nomeadamente, a violência ou ameaça grave. Como exemplo paradigmático dos efeitos perniciosos desta construção legislativa do crime, veja-se o acórdão da Relação do Porto, de 13 de Abril de 2011, em que foi absolvido um arguido, médico psiquiatra, do crime de violação de uma paciente, mulher grávida em fim de tempo e emocionalmente frágil, porque padecia de depressão (Sottomayor, 2011). Considerando o Tribunal da Relação provada a falta de consentimento da mulher, entendeu que não estava preenchido o requisito de «violência», para o efeito de uma condenação por crime de violação, fundamentando a decisão na falta de resistência da vítima e na ausência de um «debate» ou «luta» entre agressor e vítima. E não se diga, a este propósito, que as reformas da lei não devem 
surgir a reboque de um caso mediático. A conceção que exige o uso da força física (como vis absoluta ou como vis compulsiva) e um ónus de resistência à vítima, continua a ser defendida pela doutrina penalista de referência (Dias, 2013: 726) e foi aplicada noutros casos da jurisprudência publicada, mesmo que a vítima seja menor de idade e filha do agressor ${ }^{2}$ ou mulher com uma personalidade frágil e que assistiu à violência sexual do pai contra a mãe, durante a infância, sofrendo, por isso, de um choque de imobilidade perante um ataque à sua pessoa $^{3}$. A jurisprudência ${ }^{4}$ chega ao contra-senso de aplicar a exigência de uma «oposição resoluta e séria» quando está em causa um tipo legal de ato sexual com adolescente (abuso de inexperiência), que pressupõe o consentimento da vítima e, portanto, não exige violência (Sottomayor, 2003: 28-31).

Apesar das sucessivas reformas feitas aos crimes sexuais a partir do Código Penal de 1982, a lei penal não é neutra nem tão depurada de preconceitos como se pretendeu.

O legislador, ao tipificar os contornos do tipo legal de violação, baseou-se no mito de que a violação é praticada por um estranho que usa violência física ou ameaça grave contra a vítima ou que a coloca em estado de inconsciência ou na impossibilidade de resistir.

$\mathrm{Na}$ verdade, a violação é praticada, normalmente, por um homem conhecido da vítima, com quem esta tem uma relação de proximidade ou de confiança ${ }^{5}$, muitas vezes, durante uma etapa inicial de um relacionamento sexualizado ou romântico, o chamado date rape, e não envolve o uso da força física nem deixa marcas físicas de violência visíveis no corpo da vítima.

No caso da mulher casada ou que vive em coabitação marital, a violação é cometida pelo marido ou companheiro, pelo ex-companheiro ou ex-marido, surgindo como uma das etapas de agressão mais intensa antes do homicídio, no ciclo de violência doméstica a que as mulheres estão sujeitas.

2.2. É urgente fazer uma alteração à lei penal portuguesa, para que fique de acordo com a Convenção de Istambul e com a jurisprudência do Tribunal Europeu dos Direitos Humanos, que concebe a violação como um crime contra a

2 Tribunal da Relação de Guimarães, de 16-03-2009 (Relator: TOMÉ BRANCO), in Base JurídicoDocumental do MJ, www.dgsi.pt, referindo-se ao conceito de violência do tipo legal de violação: «Não basta, para integrar o conceito de violência deste crime, a existência de um apertado controlo e de uma evidente manipulação de sentimentos, por parte de quem tem uma preponderância natural sobre a vítima».

3 Acórdão do Tribunal Coletivo do 2. ․ Juízo Criminal de Cascais, de 19-3-96 (Relator: João CuRA MARIANO), CJ, 1997, Tomo II, p. 285.

4 «Inexperiente tem de gritar», Decisão instrutória de 1997.04.29 do Tribunal de Círculo de Santa Maria da Feira, Proc. 117/97, Sub Iudice, Jan.-Março/1998, pp. 1-4.

5 RASI 2013, p. 70: Nos inquéritos participados em 2013, o tipo de relacionamento autor-vítima foi o seguinte: Relações de assistência - 2; Outro - 3; S/ref. - 75; Relações familiares - 108; Desconhecido - 121; Relações de conhecimento - 164. 
liberdade de consentimento e de autodeterminação sexual, sem exigir qualquer ónus de resistência às vítimas (M.C. versus Bulgária) ${ }^{6}$.

$\mathrm{O}$ alargamento do conceito de violação na lei penal corresponde a um imperativo ético de criminalização imposto pelo quadro axiológico da Constituição, que, nos arts. 25..$^{\circ}$,.$\stackrel{\circ}{1} 1$ e $26 . .^{\circ}$, n. ${ }^{\circ} 1$, consagra o direito à integridade pessoal e ao livre desenvolvimento da personalidade, abrangendo a tutela da liberdade e autodeterminação sexual. Trata-se de valores profundos, interiores à pessoa, à sua identidade e autonomia, que implicam um poder de disposição sobre si mesma e de não tolerar intromissões alheias. Estes direitos, por força da natureza descrita, podem ser agredidos por meios que não envolvem nem ameaças nem ofensas à integridade física.

A lei penal deve, assim, ser alterada de forma a clarificar que os atos sexuais descritos nos arts 163. ${ }^{\circ}$, n. ${ }^{\circ} 1$ e $164 .{ }^{\circ}$, n. ${ }^{\circ} 1$ do CP são puníveis porque falta o consentimento de uma das partes ou porque esse consentimento não foi livre, passando a existência de violência física ou de ameaça grave a constituir causa agravante da pena.

O consentimento para um ato sexual deve ser voluntária e livremente expresso, específico para cada ato e livremente revogável, em qualquer momento. A ausência de consentimento pode ser expressa por qualquer meio: de forma verbal ou não verbal, por gestos ou expressões de medo ou de repulsa. Não tem de ser acompanhada por atos físicos de resistência ou de oposição. A noção de consentimento pressupõe, em regra, atos positivos e de colaboração, ou uma conduta ativa. $\mathrm{O}$ silêncio não pode ser identificado com consentimento. Nestes contextos, o silêncio resulta do medo e do estado de terror da vítima, da dissociação de personalidades que a paralisa, ou da consciência da inutilidade de qualquer reação.

O crime de coação sexual também deve ser alargado a todos os atos sexuais não consentidos e não apenas aos classificados pela lei como atos sexuais de relevo, integrando-se, assim, o crime de importunação sexual no crime de coação

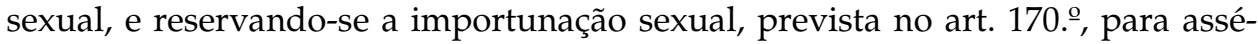
dios verbais ou atos de exibicionismo. Na verdade, a característica do ato sexual que o torna de «relevo» para a vítima não será tanto os seus contornos objetivos em si mesmos, mas a falta de consentimento para a sua prática.

Na vigência do Código Penal de 1886, a jurisprudência do Supremo Tribunal de Justiça, chegou a defender que «deve entender-se que existe o elemento violência sempre que o ato é praticado contra ou sem a vontade da vítima», equiparando-se assim a violência à ausência de vontade da vítima (Beleza dos Santos, 1924-1925). Este entendimento continua em vigor, hoje, para alguma jurisprudência mais contemplativa dos direitos das mulheres e da sua dignidade humana. herlands Institute of Human Rights, Utrecht School of Law, ECHR M_C_v_Bulgaria Publication 2003-XII. 
Contudo, persistem, lado a lado, duas correntes jurisprudenciais: aquela que exige o ónus de resistência e a que se basta com a falta de consentimento.

Daí a necessidade de intervenção legislativa para alargar o conceito de violação, promovendo-se assim, para além dos direitos à liberdade e à autodeterminação sexual, a igualdade de todos os cidadãos perante a aplicação da lei penal. Com efeito, não é admissível, num Estado de Direito, que o mesmo comportamento seja classificado como crime nuns casos e como meramente imoral noutros, atingindo esta desigualdade, quer as vítimas, quer os agressores.

Tem sido esgrimida contra este alargamento da criminalização uma alegada dificuldade da prova da ausência de consentimento ${ }^{7}$. Ora, nos crimes violentos, como se tem entendido já para a violência doméstica, o meio de prova fundamental consiste nas declarações da vítima, consideradas a prova rainha ${ }^{8}$. Para além destas declarações, os exames médico-legais e relatórios dos sintomas psicológicos de vitimação e as declarações de testemunhas ligadas emocionalmente à vítima e que tenham observado as consequências traumáticas do crime para esta, também são meios de prova que corroboram a palavra das vítimas.

A prova da falta de consentimento, enquanto elemento interno da vontade, não é nova para os tribunais, tendo que se fazer também noutros tipos legais de crime. Por outro lado, eventuais dificuldades probatórias só são relevantes a jusante, no concreto processo judicial intentado - nuns casos prova-se a falta de consentimento, noutros não se reúne prova suficiente - e não na definição dos tipos legais de crime, a qual segue uma formulação geral e abstrata, numa perspetiva de dever ser, relacionada com a hierarquia dos bens jurídicos e não com questões probatórias. Estas assumem uma dimensão exclusivamente casuística, competindo a sua análise ao processo penal e à psicologia da justiça, e não ao legislador.

Este argumento da dificuldade de prova para fundamentar o não alargamento do crime de violação aos atos praticados sem consentimento está relacionado com a defesa social dos homens que receiam ser réus em processos-crime de violação com base em alegações falsas das mulheres. A exigência de violência adicional ao ato não consentido permitiria, assim, que só fossem objeto de ação penal os casos que deixassem marcas físicas de violência no corpo da vítima, obtendo-se uma prova segura dos factos e protegendo os acusados de falsas alegações. $\mathrm{O}$ «fantasma» das falsas alegações é sempre levantado quando há uma queixa de violação ou de outro crime sexual, mas já não é esgrimido quanto a

7 Cf. Intervenção parlamentar da deputada Teresa Anjinho a propósito do projeto de lei n. $\mathrm{o}$ 522/XII (3. ${ }^{-a}$ - Altera a previsão legal dos crimes de violação e coação sexual no Código Penal (BE), disponível in http://www.parlamento.pt/Intervencoes/Paginas/DetalheIntervencao. aspx?BID=192934, consultada a 8-03-2014.

8 Vide acórdão da Relação de Lisboa, de 06-06-2001 (Relator: Adelino Salvado), Base JurídicoDocumental do MJ, wwww.dgsi.pt e acórdão da Relação de Coimbra, de 09-03-2005 (Relator: Belmiro Andrade), CJ, 2005, Tomo II, pp. 36-39. 
queixas de outros crimes, como furto ou roubo, em que não se põe em causa nem se discute a credibilidade das vítimas nem a questão do consentimento. Na verdade, sabe-se que a taxa de alegações falsas de violação é muito baixa e inferior à taxa de alegações falsas de outros crimes (Krahe e Temkin, 2008). Em relação às queixas apresentadas em Portugal por violação, os dados estatísticos disponíveis apontam para uma taxa de 5\% (Santos, 2009: 8).

O receio de alegações falsas no contexto dos crimes sexuais é o fruto de uma cultura de raízes misóginas, que desconfia das vítimas e que valoriza mais o estatuto social dos homens do que o das mulheres. A possibilidade de alegações falsas existe em qualquer crime, mas tal fenómeno não influenciou as definições dos tipos legais nem o tratamento das vítimas.

O tratamento das vítimas de violação, durante o processo, faz com que a taxa de desistência das vítimas seja elevada - cerca de 39\% desistiram na fase do inquérito (Santos, 2009: 7) - o que reflete a falta de confiança das vítimas na justiça e a ausência (ou não aplicabilidade) de medidas de proteção para evitar a vitimização secundária.

Para fazer face às dificuldades das vítimas durante o processo, os Estados Partes da Convenção de Istambul, entre várias medidas de apoio social, psicológico, jurídico e económico às vítimas, terão que lhes disponibilizar os meios necessários à recolha da prova, num momento o mais próximo possível dos factos, devendo, para o efeito, criar centros de ajuda de emergência apropriados para vítimas de violação ou violência sexual, de acesso fácil e em número suficiente, a fim de lhes oferecer um exame médico e médico-legal, apoio em caso de trauma e aconselhamento (art. 25. ㅇ).

2.3. A Convenção de Istambul, no seu art. 55.ํ, sob a epígrafe «Processos ex parte e ex officio», afirma que os Estados Parte assegurarão que as investigações ou o processamento das infrações estabelecidas nos termos dos artigos 35.. , 36. , 37. , 38. e 39. da presente Convenção, entre as quais se inclui o crime de violação, não dependam inteiramente de uma denúncia ou de uma queixa da vítima, se a infração tiver sido cometida total ou parcialmente no seu território, e que o processo possa prosseguir mesmo que a vítima retire a sua declaração ou queixa.

Nesta norma, apesar de alguma ambiguidade, quando se afirma «não dependam inteiramente de queixa», entende-se que a desistência da vítima não é relevante, o que indicia a natureza pública do crime.

O crime de violação, mesmo nos casos em que a vítima não é menor, deve ser um crime público, podendo o MP prosseguir com a ação penal independentemente da vontade da vítima e considerando a sua desistência irrelevante. A maior parte das vítimas de violação são mulheres jovens ou adolescentes, que tendem a não denunciar o crime por padecerem, em consequência da vitimação, de stress pós-traumático, sentimentos de impotência, vergonha e medo de retaliações, e pelo facto de a violação ocorrer num contexto familiar ou relacional.

Num quadro legal, em que o bem jurídico liberdade e autodeterminação 
sexual é indisponível e está constitucionalmente protegido (arts. 25. o e 26. ${ }^{\circ}$ da CRP), o Estado deve intervir, pois as mulheres raramente apresentam queixa por sentirem que os atos sexuais em que foram envolvidas, sem o seu consentimento, não serão percecionados como violação e, ainda, devido à crença de que pertencem à sua vida privada e de que são responsáveis por eles.

Em 2006, as queixas por violação correspondiam apenas a 3,23 por 100.000 habitantes, uma taxa de queixa das mais baixas da UE (Santos, 2009: 5).

Num inquérito feito a 42.000 mulheres nos 28 Estados na União Europeia, verificou-se que uma em cada dez mulheres foi vítima de alguma forma de violência sexual com 15 anos ou mais, e uma em 20 foi violada (FRA, 2014). Uma mulher em cada cinco experimentou violência física e/ou sexual do companheiro ou ex-companheiro e uma em cada dez revelou ter sido vítima de violência sexual por um adulto antes dos 15 anos. Contudo, só $14 \%$ das mulheres denunciaram o incidente de violência na relação íntima à polícia e, fora de uma relação íntima, só 13\% denunciaram a violência sofrida (FRA, 2014).

A taxa de condenações em Portugal (incluindo os casos de vítimas menores de 16 anos) também é das mais baixas da UE, tendo registado uma descida de 24\%, em 1993, para 12\%, em 2006 (Santos, 2009: 5). Para vítimas com idade igual ou superior a 16 anos, a taxa de condenações encontrada numa amostra de 100 queixas registadas como violação foi de $8 \%$ (Santos, 2009: 7). Nestes 8 casos de condenação, verificou-se que $75 \%$ dos agressores tinham antecedentes criminais, e que os factores que fazem aumentar a probabilidade de condenação são a utilização de armas, o facto de o agressor ser desconhecido da vítima e de haver ferimentos documentados (Santos, 2009: 9).

Estes dados sugerem que o sistema policial-judicial tem o estereótipo da violação como crime cometido por um estranho, que a vítima não goza de apoios e de proteção durante o processo penal e que a natureza particular ou semi-pública do crime de violação pode ser uma fonte de atrito.

Durante séculos de história, as mulheres foram sistematicamente violadas na família, na rua ou no trabalho, na guerra - e continuam, a sê-lo, hoje. É provavelmente o crime de cifras negras mais elevadas e em que se reflete mais a desigualdade histórica entre homens e mulheres.

A natureza particular do crime, fazendo a intervenção do Estado depender de queixa da vítima, perpetua o sistema do silêncio e permite a continuação da violência sexual contra as mulheres e a sua impunidade.

As sociedades patriarcais disseram às mulheres, durante milhares de anos, através do direito, da cultura, das religiões e dos costumes, que o seu corpo era propriedade dos maridos, que não tinham direito de decidir sobre ele e sobre a sua sexualidade, que não lhes pertencia. A violência sexual foi vivida como um fenómeno inerente à vida privada das mulheres e à natureza feminina. Fazia parte da condição de ser mulher e era imutável como um destino. Tinha de ser silenciada, sob pena de estigmatização social, ainda hoje visível na culpabilização sistemática das vítimas ou na desacreditação do seu testemunho. 
No ambiente social descrito, não pode dizer-se que as mulheres disponham de liberdade para decidir apresentar queixa, e que essa decisão lhes deva ser delegada. A tradição de privacidade e de silêncio em que se deu o seu processo de socialização relativamente à violência sexual impõe-se à sua vontade mais profunda de justiça e de reparação. Esta só surge num contexto social em que as vítimas não sejam culpabilizadas e em que o Estado as apoie.

Para além deste processo psicossocial de silenciamento, sobre o qual a maior parte das mulheres não tem controlo nem poder, não se pode olvidar que muitas mulheres são alvo de ameaças e de retaliações dos autores dos crimes para não denunciarem e que estes são, geralmente, os seus próprios maridos ou companheiros, ou indivíduos conhecidos e detentores de maior poder social e económico do que elas.

Invocar a «vergonha» sentida pelas vítimas para não tornar o crime público é usar a discriminação histórica das mulheres para perpetuar essa mesma discriminação. Fundamentar a natureza particular ou semi-pública do crime de violação na necessidade de proteger as mulheres contra a vitimização secundária provocada pelo processo-crime e contra a devassa da sua "vida privada», é esquecer que é obrigação do Estado consagrar medidas de proteção das vítimas de crimes violentos durante o processo penal (por exemplo, apoio psicológico e jurídico, afastamento do agressor sempre que a vítima presta depoimento, proibição de perguntas discriminatórias nos interrogatórios, direitos de informação e de participação das vítimas, conforme previsão do art. 56. ํ da Convenção), criar um corpo de profissionais da psicologia e do direito para atender e apoiar as vítimas e exigir formação especializada aos/às juízes/as que decidem estes casos e aos/às advogados/as que representam as vítimas e os agressores, bem como aos procuradores ou polícias que recebem a queixa e investigam os factos (art. 15. da Convenção).

Para as vítimas, a perda de auto-estima e a sensação de desvalorização do «eu» resultantes do silêncio perante o crime são danos psíquicos mais graves do que o eventual dano da participação no processo ${ }^{9}$, tanto mais que as ordens jurídicas atuais já contêm medidas de proteção de testemunhas. Por outro lado, a participação no processo penal pode ter um efeito catártico que ajuda a vítima na sua recuperação psicológica.

O discurso da vitimização das mulheres nem sempre é apoiado, por se entender que perpetua o estereótipo de subordinação das mulheres e da sua falta de poder. Contudo, o estatuto de vítima ou de ofendida, em processo penal, corresponde a uma exigência da lei e nesse sentido é um conceito jurídico, sem conotação inferiorizadora das pessoas a quem é atribuído. Por outro lado, é-se vítima porque se é pessoa, titular de direitos fundamentais que foram violados, e o reconhecimento do estatuto de vítima é uma consequência do reconhecimento desses direitos.

Para uma análise dos estudos feministas sobre o silêncio das mulheres vítimas de violência, como o resultado da opressão do poder patriarcal sobre elas, vide WEST, 1997: 264 -276. 
A tendência da lei, por pressão de diretivas comunitárias e convenções internacionais, tem sido a de conferir maior protagonismo às vítimas de crimes violentos, no processo penal, através do reconhecimento de direitos de informação e de participação, bem como de medidas de proteção contra a vitimização secundária. É certo que o discurso social da vitimização deve ser integrado por respostas práticas de atribuição de poder às mulheres. Mas, para combater o silêncio e a falta de acesso das mulheres aos meios necessários para a sua emancipação, é essencial, na fase da evolução social em que nos encontramos, o reconhecimento de que estas precisam da intervenção oficiosa do Estado, pois de outra forma será muito difícil enfrentarem sozinhas o sistema social e judicial, restando-lhes como alternativa, que não corresponde a uma decisão livre de não apresentar queixa, viver, em silêncio e isolamento social, a dor e a humilhação geradas pelo crime, perpetuando-se os danos da violação.

A violação não pertence ao domínio da vida privada das mulheres. É uma questão de interesse público, que compete ao Estado investigar e punir. Vale, neste contexto, a máxima feminista «o que é privado é público; o que é pessoal é político».

A perseguição penal dos violadores constitui um contributo decisivo para a igualdade de género e para um ambiente social em que os direitos à liberdade e à autodeterminação sexual das mulheres sejam mais respeitados, aumenta a censura social destes crimes e contribui para a recuperação psicológica das vítimas. É o Estado que se compromete com as mulheres a assumir a seu cargo a perseguição criminal dos violadores, sem deixar para as vítimas a angustiosa decisão de ter, ou não, a iniciativa, de apresentar queixa. Transmite-se, em simultâneo, aos violadores, a mensagem segundo a qual o clima de silêncio, que facilita a prática do crime e a impunidade, tende a terminar e que serão responsabilizados pelos seus atos.

A natureza pública do crime assume, assim, uma finalidade de prevenção geral, dissuadindo os potenciais agressores da prática do crime, envolve mais as entidades competentes na investigação, e, protegendo as vítimas, potencia o aumento da colaboração destas no processo penal.

Nem é verdade, como se tem argumentado ${ }^{10}$, que as mulheres fiquem privadas do seu poder de decisão com a natureza pública do crime, pois a lei já prevê a possibilidade de o Ministério Público, mediante um requerimento livre e esclarecido da vítima, determinar a suspensão provisória do processo penal, com a concordância do juiz de instrução e do arguido, ao abrigo do art. 281..$^{\circ}$ n. .6 do $\mathrm{CPP}$, norma que, apesar de prevista para os crimes de violência doméstica, pode ser alargada aos casos de violação.

10 Cf. Intervenção da deputada Isabel Moreira, no Parlamento, a propósito do projeto de lei n. ${ }^{\mathrm{o}}$ 522/XII (3. ) - Altera a previsão legal dos crimes de violação e coação sexual no Código Penal (BE), disponível para consulta in http://www.parlamento.pt/Intervencoes/Paginas/DetalheIntervencao.aspx?BID=192932, consultado em 08-03-2014. 


\section{Assédio sexual nas ruas e no trabalho}

3.1. O art. 40. da Convenção, sob a epígrafe «Assédio sexual», impõe aos Estados o dever de tomar as medidas legislativas ou outras necessárias para assegurar que qualquer tipo de comportamento indesejado de natureza sexual, sob forma verbal, não-verbal ou física, com o intuito ou o efeito de violar a dignidade de uma pessoa, em particular quando cria um ambiente intimidante, hostil, degradante, humilhante ou ofensivo, seja passível de sanções penais ou outras sanções legais.

Trata-se de um comportamento que atinge de forma desproporcional - desproporção ainda mais acentuada do que no crime de violência doméstica - as mulheres e as adolescentes do sexo feminino, constituindo, por excelência, um caso de violência de género. $\mathrm{O}$ inquérito a mulheres dos 28 Estados da UE divulgou que $38 \%$ das mulheres inquiridas entre 18 e 39 anos de idade tinham sido vítimas de assédio sexual, nos últimos 12 meses, incluindo o conceito de assédio comentários jocosos e ofensivos, comentários intrusivos sobre a aparência física, comentários de conotação sexual e intimidatórios, exibição de material pornográfico, olhares inapropriados e toques furtivos no corpo (FRA, 2014: 106-108). 55\% do total das mulheres inquiridas foi vítima de alguma das formas de assédio sexual descritas ao longo da sua vida (FRA, 2014: 167). Nos incidentes mais graves, em $42 \%$ dos casos, o perpetrador é um desconhecido, seguido, em $18 \%$ dos casos, de assédio no trabalho por colegas, superiores hierárquicos ou clientes (FRA, 2014: 113). A vasta maioria dos autores dos incidentes de assédio sexual mais graves são homens (FRA, 2014: 113).

O assédio sexual está legitimado por uma cultura sexista permissiva com a agressividade sexual masculina e que presume a disponibilidade sexual das mulheres para os homens, transmitindo às adolescentes, que circulam na rua, a sensação de o seu corpo ser um objeto sexual dos homens. As meninas, desde os primeiros sinais de puberdade, são despojadas do seu sentimento de pertença a si mesmas e o medo da violação ou de outras agressões sexuais passa a fazer parte da sua vida e a dominar a sua existência. Como defesa contra este sentimento, muitas adolescentes e mulheres jovens reagem, negando a presença de si mesmas no seu corpo ou tornando a sua presença no mundo menos visível, como se não merecessem o tempo e o espaço, prejudicando este sentimento a afirmação pessoal e o próprio direito a existir (Rich, 1979: 242-244).

Entendo que o assédio sexual nas ruas e no trabalho deve ser criminalizado, sendo insuficiente a sua classificação como contra-ordenação grave, conforme previsto no art. 29. do Código de Trabalho, pois trata-se de comportamentos que violam direitos fundamentais das mulheres: direitos à integridade pessoal e ao livre desenvolvimento da personalidade consagrados na Constituição (arts. 25.․ , n. 1 e 26. ${ }^{\circ}$, n..$^{\circ} 1$ da CRP) e que abrangem o «direito a não ser molestada» (Beleza, 1998: 92). A violação de direitos fundamentais assume dignidade penal: não estão em causa bens jurídicos coletivos como a moral social ou os bons costumes, 
mas bens jurídicos que fazem parte do quadro axiológico plasmado no catálogo dos Direitos, Liberdades e Garantias da Constituição, em relação aos quais se impõe a proteção através do direito penal, pelo seu valor simbólico para a comunidade e por razões de prevenção geral. Não é válido, portanto, o argumento da natureza subsidiária ou de ultima ratio do direito penal, com frequência invocado contra a criminalização do assédio sexual. Curiosamente, este princípio de direito penal não se aplica aos furtos de objetos de pequeno valor, cuja criminalização ninguém põe em causa. Aceita-se, sem mais, que a propriedade seja protegida pelo direito penal até ao último cêntimo, mas não que a liberdade das mulheres e das crianças seja protegida em todas as suas dimensões, o que traduz a origem patriarcal do sistema jurídico, que centraliza a censura jurídico-criminal nos ataques à propriedade e não reconhece, por tradição, o valor da liberdade sexual das mulheres.

Também não se pode afirmar, para justificar a não intervenção do direito penal, a falta de danosidade do assédio sexual nem a falta de um «desvalor da ação e do resultado» do comportamento do agente.

A dificuldade em ocupar, com segurança e liberdade, os espaços públicos e as limitações físicas e psíquicas com que as mulheres aprendem a viver desde a adolescência, fazem com que, por exemplo, na educação, as mulheres tenham mais dificuldade em ter um pensamento independente e em assumir riscos intelectuais (Rich, 1979: 242), o que provoca, necessariamente, uma menor participação das mulheres nos espaços públicos, na política, na vida cívica, na arte, etc. $\mathrm{O}$ assédio sexual produz, para além de danos pessoais para as mulheres, danos para toda a sociedade, pois impede a construção de uma sociedade baseada na igualdade de género.

O assédio sexual no trabalho provoca danos psíquicos e de saúde mental nas mulheres vítimas, cria angústia e ansiedade em relação à manutenção do posto de trabalho e à sua subsistência e da família, e, enquadrando-se num contexto particularmente vital para a sua qualidade de vida, pode causar suicídio ou tentativa de suicídio. O trabalho ocupa a maior parte do tempo de uma pessoa e constitui um elemento crucial para a sua auto-realização, para a relação com os outros e para a inserção da pessoa na sociedade e no mundo. $\mathrm{O}$ assédio sexual no trabalho, enquanto prática discriminatória, priva as mulheres dos seus direitos laborais e do seu valor enquanto pessoas e trabalhadoras, provocando nas vítimas um dano que se repercute na sua auto-estima, projeto de vida e relações familiares - o chamado dano existencial. Sabe-se que, segundo o inquérito feito na UE, as mulheres mais afetadas por assédio sexual no trabalho são as que ocupam cargos de responsabilidade e as que têm vínculos laborais precários ou irregulares (FRA, 2014: 111).

A dimensão da necessidade e da eficácia penal está também presente na criminalização do assédio, pois a punição de comportamentos banalizados pelos costumes é suscetível de inibir os sujeitos de os praticar, tanto mais que o assediador é um indivíduo de qualquer estrato social ou profissão, e que, em regra, tem 
conhecimentos e capacidade para se comportar de forma racional e para se orientar pelo cumprimento das normas, o que fará, se souber que será sancionado.

A criminalização do assédio sexual terá, portanto, um forte valor preventivo e simbólico, sobretudo se em conjugação com políticas sociais e de educação.

3.2. A criminalização é necessária porque os crimes sexuais já tipificados, como a coação sexual e a importunação sexual, não integram a maior parte dos comportamentos típicos do conceito de assédio, e a mera tentativa não está abrangida pelo âmbito de criminalização destas normas penais (arts. 163.․ , n.. 2, $170 .$. em conjugação com o art. 23..$^{\circ}$,.${ }^{\circ} 1$ do $\mathrm{CP}$ ).

O Código Penal prevê o tipo legal de crime de coação sexual (art. 163., n.ํㅜ 1), que pune atos sexuais de relevo praticados com violência ou ameaça grave, e também os atos sexuais de relevo praticados, sem o recurso aos meios de constrangimento do n. ${ }^{-0}$, por meio de abuso de autoridade decorrente de relação familiar, de tutela ou curatela, de dependência hierárquica, económica ou de trabalho, ou com aproveitamento do temor causado (art. 163. ${ }^{\circ}$, n.․․ 2). A lei penal pune, assim, algumas formas de assédio sexual no trabalho e na rua, mas sujeita esta punição a duas limitações: o ato sexual praticado tem que ser considerado de relevo e tem de existir abuso de autoridade, dependência hierárquica ou económica, ou aproveitamento do temor causado.

Por outro lado, a tentativa de praticar ato sexual de relevo, nas circunstâncias previstas no art. 163. ${ }^{\circ}$, n. -2 do $\mathrm{CP}$, não é punível, pois ao crime consumado respetivo corresponde pena não superior a três anos (art. 23. ${ }^{\circ}$, n. ${ }^{\circ} 1$ do $\mathrm{CP}$ ). Por outro lado, a doutrina e a jurisprudência interpretam de forma restritiva o conceito de ato sexual de relevo, deixando de fora da incriminação a maior parte das situações de assédio sexual, de natureza verbal ou gestual (Sottomayor, 2007).

A reforma ao Código Penal de 2007 (Lei n.o 59/2007, de 4 de setembro), introduziu um tipo legal de crime, designado por importunação sexual (art. 170. do $\mathrm{CP}$ ), suscetível de abranger o assédio sexual na rua ou em locais públicos, mesmo que o ato para o qual a vítima é constrangida não seja considerado um ato sexual de relevo para o efeito do art. 163. do CP (coação sexual). Todavia, não estão incluídos no âmbito da norma todos os tipos de assédio sexual, nomeadamente, as situações de abuso verbal, convites não desejados, etc. $\mathrm{O}$ art. 170. do $\mathrm{CP}$ pune atos de exibicionismo e o constrangimento a atos sexuais, exigindo, nesta segunda hipótese, que exista um contacto físico, de natureza sexual, não desejado. Mas a tentativa de praticar estes contatos físicos não é punida pela

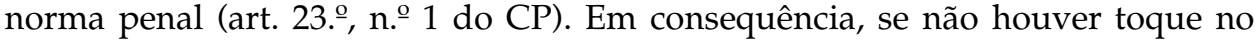
corpo, tudo o que seja abuso verbal de conteúdo sexual, que é também ofensivo e perturbador da integridade e da liberdade das mulheres, bem como sinal de ameaça iminente de agressão sexual, não está penalizado, a não ser nos casos em que a vítima seja uma criança com menos de 14 anos, uma vez que o crime de abuso sexual de crianças, no art. 171.ํ, n. 3 , alínea b) CP, abrange as conversas de teor sexual, a exposição a escrito, espetáculo ou objeto pornográficos. Contudo, a 
partir dos 14 anos, as adolescentes não estão protegidas contra o assédio verbal, a não ser que se possa integrar essa verbalização no tipo legal de crime de difamação (art. 180. do CP) ou de injúria (art. 181. do CP). Contudo, o conteúdo sexual, humilhante e invasivo, contido nas palavras não está abrangido naquilo que se entende ser um crime de injúria ou de difamação, nem o bem jurídico protegido por estas normas penais é o mesmo que é violado com o assédio sexual. A injúria e a difamação protegem o bom nome de uma pessoa, a sua honra ou consideração. Já a penalização do assédio sexual nas ruas visa proteger a liberdade, o livre desenvolvimento da personalidade e a autonomia, bens jurídicos mais profundos, íntimos e integradores da personalidade do que o bom nome. $\mathrm{O}$ assédio sexual nas ruas distingue-se, também, dos tipos legais de crime de injúria e difamação pela intencionalidade e significado social que lhe preside: pressão sobre as mulheres, induzindo-as a permanecer no espaço privado e a excluírem-se do espaço público; expressão de desprezo pelas mulheres pelo facto de o serem; redução da pessoa assediada ao estatuto de objeto sexual.

O assédio sexual tem uma componente de violência de género e de hierarquia, na medida em que se trata de um comportamento que atinge de forma desproporcionada as mulheres e que é praticado por homens na maioria dos casos, o que não sucede no crime de injúria, que pode ocorrer em contextos de relação de igualdade e entre pessoas do mesmo género e sem relação hierárquica entre si. Para além disto, a integração do assédio sexual no crime de injúria, não nomeando o comportamento através de uma linguagem que reflita a experiência das vítimas, perpetua o silêncio.

Ao contrário das crenças populares, não se trata de uma brincadeira inofensiva ou de um elogio à beleza feminina, sem consequências. A frequência com que estas agressões são praticadas provoca nas adolescentes medo de sair à rua, deixando de exercer a sua liberdade ou, pelo menos, não a exercendo com a tranquilidade e a segurança a que têm direito como pessoas, titulares de direitos fundamentais. É do conhecimento comum que as meninas e as mulheres, quando andam sozinhas nas ruas, sobretudo à noite, fazem-no "transidas de medo" (Beleza, 1984: 24), medo que funciona como um instinto de defesa e de alerta, que impede as sensações de liberdade e de autonomia, tão importantes para o desenvolvimento da pessoa humana, para a realização das suas potencialidades e para a alegria de viver. Tal como a sexualidade não é apenas um fenómeno físico, também a ofensa à liberdade sexual não envolve necessariamente contatos físicos. A palavra também pode consistir numa forma de praticar um crime, que ofende a liberdade, a integridade psicológica e a autodeterminação sexual de uma pessoa.

\section{Conclusão}

A definição legal de violação e de coação sexual deve adequar-se à realidade da vida das mulheres e à sua experiência, abrangendo todos os atos sexuais 
não consentidos, independentemente da utilização de meios de constrangimento, como a violência ou a ameaça grave

O assédio sexual deve ser sancionado penalmente porque constitui um comportamento que viola os direitos humanos das mulheres à liberdade, à integridade pessoal e ao livre desenvolvimento da personalidade. A impunidade deste comportamento perpetua a desigualdade de género e o estatuto social inferior das mulheres, causando danos psicológicos graves às vítimas e a toda a sociedade, pois compromete a construção da igualdade de género.

\section{Abreviaturas}

CJ - Colectânea de Jurisprudência

$\mathrm{CP}$ - Código Penal

CPP - Código de Processo Penal

CRP - Constituição da República Portuguesa

FRA - European Union Agency for Fundamental Rights

MJ - Ministério da Justiça

MP - Ministério Público

RASI - Relatório Anual de Segurança Interna

UE - União Europeia

\section{Referências Bibliográficas}

Beleza, Teresa Pizarro (1984), A Mulher no Direito Penal, Cadernos da Comissão da Condicão Feminina, n.․ 19, Lisboa.

Beleza, Teresa Pizarro (1998), «A revisão da parte especial na reforma do Código Penal: legitimação, reequilíbrio, privatização, «individualismo», in Jornadas sobre a revisão do Código Penal, Maria Fernanda Palma/Teresa Pizarro Beleza (organizadoras), Lisboa, AAFDL, pp. 89-118.

Dias, Jorge de (2013), "Comentário ao artigo 163. do Código Penal», in Comentário Conimbricense do Código Penal, Parte Especial, Tomo I (dirigido por Jorge de Figueiredo Dias), Coimbra, Coimbra Editora.

FRA, European Union Agency for Fundamental Rights (2014), Violence against Women: an EU-Wide survey, Main results, Viena, Aústria, disponível para consulta in http:// fra.europa.eu/sites/default/files/fra-2014-vaw-survey-main-results-apr14 en.pdf, consultado a 12-01-2015.

Krahe, Barbara; Temkin, Jennifer (2008), Sexual Assault and the Justice Gap: A Question of Attitude, Oxford, Hart Publishing.

RASI (2013), Relatório Anual de Segurança Interna, disponível in http://www.portugal. gov.pt/media/1379710/RASI\%202013.PDF, consultado a 12-01-2015.

Rich, Addrienne (1979), «Taking Women Students Seriously», in Lies, Secrets, and Silence, New York. London, W. W. Norton \& Company.

Santos, Beleza dos (1924-1925), «O crime de violação», RLJ, Ano 57.․, p. 369.

Santos, Jorge Costa et al. (2009), Different systems, similar outcomes? Tracking attrition in reported cases in eleven countries, European Comission DAPHNE II Programme Project 
n..$^{\circ}$ JLS/DAP/06-1/141/WYC, Delegação do Sul do Instituto Nacional de Medicina Legal, I.P., Lisboa.

Sottomayor, Maria Clara (2003), «O poder paternal como cuidado parental e os direitos da criança», in Cuidar da Justiça de Crianças e Jovens, A função dos juízes sociais, Atas do encontro (coordenação Maria Clara Sottomayor), Coimbra, Almedina, pp. 9-63.

Sottomayor, Maria Clara (2007), O método da narrativa e a voz das vítimas de crimes sexuais, Revista Eletrónica de Direito Constitucional \& Filosofia Jurídica, Vol. I, disponível para consulta in http:/ / constitutio.tripod.com/id7.html, consultada em Agosto de 2013.

Sottomayor, Maria Clara (2011), «O conceito legal de violação: um contributo para a doutrina penalista», Revista do Ministério Público, n.o 128, Out.-Dez. 2011, pp. 273-318.

West, Robin (1997), Caring for Justice, New York University Press.

Maria Clara Sottomayor é Juíza Conselheira do Supremo Tribunal de Justiça, desde Setembro de 2012, e Professora convidada na Escola de Direito do Porto da Universidade Católica Portuguesa, instituição em que obteve o grau de Doutoramento em Direito Civil. Autora de várias publicações, entre as quais, Regulação do exercício das responsabilidades parentais nos casos de divórcio, em 6." edição e Temas de Direito das Crianças, bem como artigos publicados em revistas jurídicas nas áreas do Direito da Família e das Crianças, do Direito das Mulheres e do Direito Civil.

Centro de Estudos e Investigação em Direito da Universidade Católica Portuguesa Rua Infante Santo, 514, 6.-.A, 4150-405 Porto sottomayorclara@gmail.com

Artigo recebido em 30 de setembro de 2014 e aceite para publicação em 3 de fevereiro de 2015. 